\title{
Is There a Place for Cross-cultural Contastive Rhetoric in English Academic Writing Courses?
}

\author{
Lin Zhou \\ University of Illinois at Urbana Champaign, USA
}

Article received 14 August 2015, accepted 15 November 2015, final version received 4 February 2016 http://dx.doi.org/10.5565/rev/jtl3.645

\begin{abstract}
This is a primary study investigating the pedagogical approach of employing crosscultural contrastive rhetoric (CCCR) comparisons in graduate-level writing courses. Two 501-level (advanced) classes were recruited to participate in this study: one class received CCCR instruction and participated in CCCR discussions, and the other class did not receive CCCR instruction and discussions. The study entailed both quantitative and qualitative investigations involving the grading of the results, the counting of use of dependent clauses and cohesive devices in students' writing samples; pre- and post-study surveys, questionnaires and interviews. The findings show that students who received CCCR instruction and participated in CCCR discussions demonstrated more active use of connectives and showed increased metacognition about the similarities and differences between English academic writing academic writing in their L1s.
\end{abstract}

Key words: contrastive rhetoric; English academic writing; metacognition; pedagogical approach; dependent clauses; connectives

\section{Resumen}

Este artículo se trata de un estudio diseñado para investigar el enfoque pedagógico de emplear la retórica contrastiva y la comparación entre culturas (cross-cultural contrastive rhetoric o CCCR en inglés) en los cursos de escritura a nivel de postgrado. Dos clases de nivel advanzado fueron reclutados para participar en este estudio: una clase recibió instrucción CCCR y participó en las discusiones relacionados al enfoque CCCR, y la otra clase no recibió instrucción CCCR ni discusiones. El estudio utilizó investigaciones cuantitativas y cualitativas que consistieron en la clasificación de los resultados, el recuento del uso de las cláusulas dependientes y cohesión del texto en las muestras de escritura de los estudiantes; encuestas pre- y post-estudio, cuestionarios y entrevistas. Los resultados muestran que los estudiantes que recibieron instrucciones CCCR y participaron en las discusiones CCCR demostraron un uso más activo de los conectivos y mostraron un aumento de la metacognición acerca de las similitudes y diferencias entre la escritura académica en la lengua meta (inglés) y la L1 de los estudiantes.

Palabras clave: retórica contrastiva; escritura académica en inglés; metacognición; diseño pedagógico; clausulas dependientes; conectivas

\section{Resum}

Aquest article es tracta d'un estudi dissenyat per investigar l'enfocament pedagògic d'emprar la retòrica contrastiva i la comparació entre cultures (cross-cultural 
contrastive rhetoric o CCCR en anglès) en els cursos d'escriptura a nivell de postgrau. Dues classes de nivell avançat van ser reclutats per participar en aquest estudi: una classe va rebre instrucció CCCR i va participar en les discussions relacionats a l'enfocament CCCR, i l'altra classe no va rebre instrucció CCCR ni discussions. L'estudi va utilitzar investigacions quantitatives i qualitatives que van consistir en la classificació dels resultats, el recompte de l'ús de les clàusules dependents i cohesió del text en les mostres d'escriptura dels estudiants; enquestes pre- i post-estudi, qüestionaris i entrevistes. Els resultats mostren que els estudiants que van rebre instruccions CCCR i van participar en les discussions CCCR van demostrar un ús més actiu dels connectius i van mostrar un augment de la metacognició sobre les similituds i diferències entre l'escriptura acadèmica en la llengua meta (anglès) i la L1 dels estudiants.

Paraules clau: retòrica contrastiva; escriptura acadèmica en anglès; metacognició; disseny pedagògic; clàusules dependents; connectives

\section{Introduction}

The theoretical basis for the thesis is contrastive rhetoric - the study of how one's first language influences his/her writing in a second language (English in this study) and the dynamic model of academic writing that calls for students' metacognition instead of prescriptive pedagogies. The focus of the article is not on looking for the differences between students' L1s and English in the areas of academic writing, but the pedagogical applications based on the existing studies of contrastive rhetoric studies. The subjects of the study are students in the Writing Service Courses in the University of Illinois at Urbana-Champaign, which according to the university official website, has the largest international student population of any public institution in the U.S. with almost 10,000 students from abroad on campus. According to International Student Scholar Services of University of Illinois, the total number of international students in Fall 2014 is 9824.

As is indicated in the literature review below, the detected limitations of traditional contrastive rhetoric have led to a new model and approach towards contrastive rhetoric in teaching students to write in a foreign language. Kubota and Lehner (2004) have suggested critical contrastive rhetoric, which recognizes students' identities, the rhetorical forms and multiplicity of languages, which is in line with the dynamic model of L2 writing employing contrastive rhetoric. This call for a new perspective of the contrastive rhetoric emphasizes the cultural aspect. Thus, this research defines the dynamic cross-cultural contrastive rhetoric (CCCR) as the explicit instruction of students on the similarities and differences between their L1 
writing and L2 writing and actively involving them in the finding of such similarities and differences in their academic writing in their L1s and English academic writing.

The instruction of dynamic CCCR does not aim to teach the cross-cultural differences in rhetoric as a fact but as a starting point for students to reflect on their past experience of writing in both their L1s and L2. The instruction covers both the similarities and differences to craft a general picture of CCCR of both languages to students so that they could understand that academic writing is not only about following templates or rules. The areas for investigation include both the study of the organization and the language because, as Quinn (2012) has concluded, the direct learning of rhetorical patterns can benefit students' L2 writing in English and allow them to function better in the new discourse community.

Following these lines of inquiry, this study investigated whether cross-cultural contrastive rhetoric activities would facilitate ESL students in understanding the possible gap between their understanding of English academic writing and the expectations of English academic writing, and whether a pedagogical approach employing CCCR activities would improve students' metacognition and prompt them to change their previous ways of writing.

The research used an existing ESL writing service course as the experimental group, and another class of the same level that followed the same curriculum as the control group. All students in the control group received cross-cultural contrastive rhetoric (CCCR) lessons as part of their instruction. Pre-instruction surveys, unit feedback, and post-instruction interviews supplemented the instruction over the course of the semester. The question of the research is whether students' awareness of cross-cultural contrastive rhetoric of Academic Writing in students' L1s and English Writing has a positive correlation with the performance of English writing.

\section{Literature Review}

The literature review demonstrates that the prospect of contrastive rhetoric has experienced an increased presence, indicating an increasing significance in L2 writing classes. Early studies such as Leki (1991) contended that contrastive rhetoric has the greatest potential of practical application in L2 writing classes. Silva (1993) claimed that although L1 and L2 writings are similar in their broad outlines, they are different in numerous and important ways. Kachru (1997) 
opined that for the purpose of finding a typology and a set of universals of rhetorical patterns, contrasting rhetorical patterns is meaningful. More recently, Petrić (2005) pointed out that the findings from contrastive rhetoric studies could serve as indicators for general tendencies and should be tested out in the real teaching context. Walker (2011) concluded that regardless of criticism of cross-cultural contrastive rhetoric, a recent resurgence in the number of high quality pedagogical studies concerning the teaching of intercultural rhetoric in university writing classes for East-Asian (Chinese, Japanese, and Korean) writers has been observed. Furthermore, despite the increasing globalization, it has been noticed that EFL writing in Japan still demonstrates some cultural features drawn from contrastive rhetoric studies (McKinley, 2013). This seems to corroborate what Leki claimed in 1991, which is that ideally contrastive rhetoric can provide writing teachers (and students) more understanding of the cultural differences in writing.

Secondly, it has been discovered that the strong link between contrastive rhetoric and culture is a key feature of contrastive rhetoric. Carrell (1984) found that strict expository organization facilitates ESL readers in recalling information of the paper and different discourse types seemed to have different effects on ESL readers' quantity of ideas reproduced in their free written recall based on their different native languages. Similarly, Matalene (1985) argued that a culture's rhetoric constitutes an interface where the prescriptions of the language meet the practices of the culture. Liebman (1998) also remarked that students could be ethnographers of contrastive rhetoric and this helps them become more conscious of their academic discourse. Atkinson (2004) concluded that using the notion of culture to explain differences in written texts and writing practices is one of the distinctive characteristics of contrastive rhetoric, and he suggested a more flexible and inclusive interpretation and application of using culture as an analysis tool.

However, whether there is a correlation between the pedagogies of contrastive rhetoric in L2 writing and improvement of writing performance has not been conclusively proven. The understanding at the moment is that the static teaching (Matsuda, 1997) is not the ideal means of teaching L2 writing using contrastive rhetoric. The pedagogical application of insights generated from contrastive rhetoric studies have been limited by the static theory of L2 writing, which has been widely employed in teaching organizational structures. 
Parallel to studies in contrastive rhetoric, the concept of metacognition is receiving more recognition in learning. It was originally coined by Flavell (1979) and it refers to learners' own knowledge of their own thinking, and Anderson (2002) defined metacognition as "thinking about thinking" (p. 23). Metacognition leads to specific changes in how learning is conducted and strategies that generate different or better learning outcomes (Anderson, 2008). Veenman, Van Hout-Wolters and Afflerbach (2006) relate various concepts pertaining to metacognition, including metacognitive awareness, metacognitive beliefs, metacognitive knowledge, executive skills, higher order skills and self-regulation.

Lastly, various studies have confirmed the existence of differences in English writing due to varied cultural backgrounds. Kaplan (1966) described thought patterns as linear for native English speakers, parallel for native speakers of Semitic languages, indirect for native speakers of Oriental languages and digressive for native speakers of Romance languages and Russian. While this very early work in the field by Kaplan is now seen as oversimplification of these differences, this paper is critical in that it founded this field. Mauranen (1993) found that Anglo-American writers tended to reveal more writer presence in their academic writing than Finnish writers, as they appeared to use more metatext that helps to guide their readers through the structure of the paper. In terms of lower level linguistic concerns, L2 writers' texts were simpler in structure. Their sentences included more but shorter T units (Hunt, 1965), fewer but longer clauses, more coordination, less subordination, less noun modification, and less passivization. They evidenced distinct patterns in the use of cohesive devices, especially conjunctive (more) and lexical (fewer) ties, and exhibited less lexical control, variety, and sophistication (Silva, 1993). Fagan and Cheong (1987) found that Chinese students used the same traditional transitional connectives (e.g., but, and) as English writers. Tucker (1995) stated that Asian writing was intentionally nondirectional. Yang and Cahill (2008) held that Chinese expository rhetorical pattern does not differ greatly from that of English. (These studies provide theoretical basis for the choice of linguistic focus of English academic writing for this study: the use of dependent clauses and connectives).

Despite consistent findings about contrastive rhetoric between English and other languages, researchers maintain that writing should not be taught as prescription of rules and patterns generated by contrastive rhetoric research as it involves a myriad of factors. Land (1998) propagated the idea of a pluralistic US rhetoric that equipped students with necessary skills to use 
Standard English Writing to succeed in a variety of disciplines. Mohan and Lo (1985) found that greater awareness of students' native literacy and their educational factors affect students L2 academic writing.

Similar to Liebman (1998), Gebhard, Gaitan and Oprandy (1987) suggested that in writing, students and teachers should go beyond prescription and work as investigators of writing. Kubota and Lehner (2004) also critiqued traditional contrastive rhetoric as constructing a static, homogeneous, binary picture of English versus other language and also projecting English writing as a superior to other writing styles. Most importantly, traditional contrastive rhetoric assumed the automatic L1 transfer in ESL learners' writing and hence, these authors emphasized the importance of self-reflexivity in critical contrastive rhetoric.

The dynamic model of L2 writing means that teaching ESL organizational structure does not translate into prescribing patterns, but to involve "a way of raising ESL students' awareness of various factors that are involved in structuring the text” (Matsuda, 1997, p. 56). Along these lines, Atkinson (2003) has argued for a new view of L2 writing that takes into consideration of a large scale of social and cultural contexts that influence L2 writing. Similarly, Connor (2002) has stated that as cultures and genres are dynamic, contrastive rhetoric should reflect the change of patterns and norms over time. These new lines of thought concerning CCCR were integrated into the study design described below.

\section{Methodology}

The research adopts a mixed methodology in which both quantitative and qualitative analysis were involved: following the execution of the cross-cultural contrastive rhetoric instruction, quantitative data was collected and analyzed concerning use of specific language features. Also, interviews, surveys, and reflections were recorded to analyze students' metacognition development and subjective perceptions of CCCR instruction and discussions. For the pedagogical intervention (which served as both the object of study as well as the instrument for collecting data), instructors conducted CCCR instruction and discussions using three delivery modes: in-class discussion, videos, and readings. After students received CCCR instruction and finished the discussions, they submitted their findings of similarities and differences between English academic writing and academic writing in their L1s through online forms. Furthermore, a 
series of CCCR activities and discussions were integrated into the existing curriculum of ESL Writing Service Courses. ${ }^{\mathrm{i}}$

CCCR instruction and discussions focused on two major aspects: global aspects of academic writing such as rhetorical style and organization and local language aspects including use of dependent clauses and cohesive devices. Students' final performance in these areas served as the criteria of the evaluation to draw the connection between the awareness of cross-cultural contrastive rhetoric and students' writing performance.

The process of the research employs both traditional classroom setting discussions and technology-assisted videos and online forms. The instruction of the cross-cultural contrastive rhetoric was integrated into the writing service courses, separate exercise sessions addressing the instruction were created online and students were asked to complete the exercises to demonstrate their understanding of the instruction of CCCR and share their findings of cross-cultural contrastive rhetoric analysis between English academic writing and academic writing in students' L1s. The data was collected in the form of video recording, reflections, writing samples, surveys and interviews, and analyzed through transcription and cross-referencing between the control and experimental group as well as within each group.

\section{Data Collection and Analysis}

Participants in this study are all international graduate students who were required to take ESL Writing Service Courses at the graduate level. The students' native languages include: Chinese (Mandarin), Korean, Farsi, Spanish and Turkish. They also represent a large variety of academic fields. There were 14 students in each group and students were given consent forms at the beginning of the semester without the teachers' presence. According to the consent forms, twelve of each group agreed to participate in the study and gave the researcher permission to use their data, including writings, video recordings, and surveys for this study. The students' names are changed in the study to protect their identities.

Phase 1 of the study focuses on two specific elements explored by the experimental group: the use of dependent clauses and cohesive devices. Dependent clauses were chosen as one focus area here because these were the two main topics that surfaced in students' beginning-ofsemester questionnaire as well as their diagnostic analysis. Students' grammatical errors lay in 
dependent clauses and their writings in general lacked coherence. These two areas were two of the surfaced themes from students' beginning-of-semester questionnaire. However, it is important to note that the statistical analysis here is not suggesting that the number of dependent clauses and connectives is proportional to the quality of writing. The purpose of the statistical analysis is to investigate whether CCCR instruction and activities lead to more production of dependent clauses and connectives and hence demonstrate students' improvement of metacognition of CCCR. In addition, in the original research, students' numerical grades given by four ESL instructors were also quantitatively analyzed, but no significant differences were observed. This showed that students who receive dynamic CCCR instruction and participate in the CCCR discussions did not have an overall better performance in their writing assignments than their counterparts who do not receive dynamic CCCR instruction as determined by the grades given by raters. The statistical model used to analyze the data is chi-square as it is appropriate for comparison studies to determine whether the change is significant.

Phase 2 of the study focuses on students' subjective perceptions of the instruction and discussions which incorporate the concept of CCCR. Furthermore, students were also asked to rate different tools which were used to conduct these CCCR instruction and discussions. Students' reflections and ratings were compared between the experimental group and control group to demonstrate differences.

\section{Results \& Discussions of Phase 1 (Quantitative study)}

\section{Research Question 1}

Do students who receive dynamic CCCR instruction and participate in the CCCR discussions perform better than their counterparts in specific areas, including dependent clauses and cohesive devices, in comparison to those who do not receive dynamic CCCR instruction?

The following data showed students' use of dependent clauses in both the control and experimental group for their first assignment. In order to determine whether the change shown in students' writings is significant, a statistical analysis needs to be conducted to determine the significance. Chi-square test was conducted to calculate whether there is significant difference between two groups at the very beginning. Non-significant data reveals that students' uses of dependent clauses were at roughly similar level at the beginning of the semester. 
Table 1. Percentage of Use of Dependent Clauses for First Assignment from Control Group

\begin{tabular}{llccc}
\hline Pseudonym & L1 & Number of Dependent Clauses & Number of Sentences & Percentage \\
\hline Yueyue & Chinese & 5 & 23 & $22 \%$ \\
\hline Sunsun & Korean & 14 & 32 & $44 \%$ \\
\hline Kwon & Korean & 7 & 30 & $23 \%$ \\
\hline Hyun & Korean & 5 & 27 & $19 \%$ \\
\hline Oscar & Turkish & 6 & 20 & $30 \%$ \\
\hline Mengmeng & Chinese & 2 & 24 & $8.0 \%$ \\
\hline Jongjong & Chinese & 6 & 24 & $25 \%$ \\
\hline Xuxu & Chinese & 4 & 25 & $16 \%$ \\
\hline Huahua & Chinese & 4 & 17 & $24 \%$ \\
\hline Lee & Chinese & 5 & 25 & $20 \%$ \\
\hline Bobo & Chinese & 9 & 19 & $47 \%$ \\
\hline Ahmed & Turkish & 7 & 22 & $26 \%$ \\
\hline$*$ Class Average & & & &
\end{tabular}

Table 2. Percentage of Use of Dependent Clauses for First Assignment from Experimental Group

\begin{tabular}{lcccc}
\hline Pseudonym & L1 & Number of Dependent Clauses & Total Number of Sentences & Percentage \\
\hline Alma & Farsi & 2 & 15 & $13 \%$ \\
\hline Xiaochen & Chinese & 5 & 25 & $20 \%$ \\
\hline Fanfan & Chinese & 6 & 18 & $33 \%$ \\
\hline Hanhan & Chinese & 9 & 22 & $41 \%$ \\
\hline Lili & Chinese & 5 & 16 & $31 \%$ \\
\hline Songsong & Chinese & 23 & 31 & $71 \%$ \\
\hline Hengheng & Chinese & 13 & 15 & $87 \%$ \\
\hline Jiajia & Chinese & 4 & 33 & $12 \%$ \\
\hline Haohao & Chinese & 6 & 26 & $23 \%$ \\
\hline Liang & Chinese & 10 & 22 & $45 \%$ \\
\hline Kim & Korean & 7 & 22 & $32 \%$ \\
\hline Santiago & Spanish & 6 & 24 & $25 \%$ \\
\hline Ibrahim & Persian & 10 & 24 & $42 \%$ \\
\hline Minmin & Chinese & 7 & 18 & $39 \%$ \\
\hline *lass Average & & & & $37 \%$ \\
\hline
\end{tabular}

In order to determine whether there is a significant difference between the experimental group and control group, Chi-square test was conducted on the data from Table 1 and Table 2. In Table 3, numbers in the column of dependent clause and non-dependent clauses are the average of the whole class.

Table 3. Chi-Square Analysis of Dependent Clauses for First Assignment

\begin{tabular}{lcc}
\hline & Dependent Clauses & Non-Dependent Clauses \\
\hline Control Group & 6 & 18 \\
\hline
\end{tabular}


Experimental Group

8

14

Although class average of experimental group is $11 \%$ higher than the control group, there is no significant difference between two sets of data. This is because from Chi-square-test at the significance level of 0.05 , the $\mathrm{P}$-value is 0.41 . The result is not significant at $\mathrm{p}<0.05$. This shows that students' use of dependent clauses were at similar levels at the beginning of the semester. As the first assignment is an argumentative essay, students from different disciplines were asked to write an argumentative response to a provided topic. This statistical data showed a clear reflection of students' understanding of English argumentative writing.

With the similar use of dependent clauses at the beginning of the semester, findings from the use of dependent clauses at the end of the semester provided meaningful information about whether CCCR instruction and discussions improved students' use of dependent clauses. Table 2 shows the percentage of use of dependent clauses for final assignment from the control group and it could be seen that the class average for the control group is $25.21 \%$.

Table 4. Percentage of Use of Dependent Clauses for Final Assignment from Control Group

\begin{tabular}{llccc}
\hline Pseudonym & L1 & Number of Dependent Clauses & Number of Sentences & Percentage \\
\hline Yueyue & Chinese & 15 & 102 & $15 \%$ \\
\hline Sunsun & Korean & 46 & 134 & $34 \%$ \\
\hline Kwon & Korean & 20 & 105 & $19 \%$ \\
\hline Hyun & Korean & 32 & 105 & $30 \%$ \\
\hline Oscar & Turkish & 29 & 119 & $24 \%$ \\
\hline Mengmeng & Chinese & 34 & 96 & $35 \%$ \\
\hline Jongjong & Chinese & 19 & 133 & $14 \%$ \\
\hline Xuxu & Chinese & 24 & 91 & $26 \%$ \\
\hline Huahua & Chinese & 38 & 102 & $37 \%$ \\
\hline Lee & Chinese & 19 & 67 & \\
\hline Bobo & Chinese & 9 & 74 & \\
\hline Ahmed & Turkish & 25 & 97 & $12 \%$ \\
\hline$*$ Class Average & & & & $26 \%$ \\
\hline
\end{tabular}

Table 5. Percentage of Use of Dependent Clauses for Final Assignment from Experimental Group

\begin{tabular}{llccc}
\hline Pseudonym & L1 & $\begin{array}{c}\text { Total } \\
\text { Number } \\
\text { of Dependent } \\
\text { Clauses }\end{array}$ & $\begin{array}{c}\text { Total Number } \\
\text { of Sentences }\end{array}$ & $\begin{array}{c}\text { Percentage } \\
\text { of dependent } \\
\text { clauses used }\end{array}$ \\
\hline Alma & Farsi & 29 & 72 & $40 \%$ \\
\hline Xiaochen & Chinese & 28 & 129 & $22 \%$ \\
\hline Fanfan & Chinese & 40 & 68 & $59 \%$ \\
\hline Hanhan & Chinese & 45 & 114 & $39 \%$ \\
\hline Lili & Chinese & 27 & 127 & $23 \%$ \\
\hline Songsong & Chinese & 50 & 66 & $39 \%$ \\
\hline Hengheng & Chinese & 11 & & $17 \%$ \\
\hline
\end{tabular}

Bellaterra Journal of Teaching \& Learning Language \& Literature. 9.1 (Feb-Mar 2016)

ISSN 2013-6196 


\begin{tabular}{lllll}
\hline Jiajia & Chinese & 31 & 124 & $25 \%$ \\
\hline Haohao & Chinese & 35 & 134 & $26 \%$ \\
\hline Liang & Chinese & 42 & 117 & $36 \%$ \\
\hline Kim & Korean & 21 & 100 & $21 \%$ \\
\hline Santiago & Spanish & 30 & 65 & $46 \%$ \\
\hline Ibrahim & Persian & 19 & 68 & $28 \%$ \\
\hline Minmin & Chinese & 20 & 108 & $19 \%$ \\
\hline * Class Average & & & & $31 \%$ \\
\hline
\end{tabular}

Table 5 shows the data from the experimental group with the class average of $31 \%$. In order to determine whether there is a significant difference between the experimental group and control group, Chi-square test is conducted on the data from Table 4 and Table 5. In Table 6, numbers in the column of dependent clause and non-dependent clauses are the average of the whole class.

Table 6. Chi-Square Analysis of Dependent Clauses for Final Assignment

\begin{tabular}{lcc} 
& Dependent Clause & Non-Dependent Clauses \\
\hline Control Group & 26 & 76 \\
\hline Experimental Group & 31 & 69 \\
\hline
\end{tabular}

By the end of the semester, students' use of dependent clauses and connectives were calculated again. Only students from the experimental group had received specific instruction and participated in CCCR activities in the areas of connectives and dependent clauses. Comparing the two groups, it could be seen that the class average of the experimental group is $5 \%$ higher than that of the control group. Chi-square-test was used to run the data between control and experimental group in terms of use of dependent clauses for final assignment. The Chi-square statistic is 0.7568 . The $\mathrm{P}$ value is 0.384332 . This result is not significant at $\mathrm{p}<0.10$. The data shows that there is no significant difference between the use of dependent clauses for final assignment between the control group and experimental group.

Other than dependent clauses, another area of focus for CCCR instruction and discussions is connectives. Table 7 and 16 demonstrate students' use of cohesive devices from both the control and experimental group for their first assignments. The data for first assignments was collected because it served as the baseline for the comparison at the end of the semester.

Table 7. Percentage of Use of Cohesive Devices for First Assignment (Control)

\begin{tabular}{lcccc}
\hline Pseudonym & L1 & $\begin{array}{c}\text { Sentences } \\
\text { with Connectives }\end{array}$ & $\begin{array}{c}\text { Number } \\
\text { of Sentences }\end{array}$ & Percentage \\
\hline Yueyue & Chinese & 9 & 23 & $39 \%$ \\
\hline Sunsun & Korean & 12 & 32 & $38 \%$ \\
\hline Kwon & Korean & 17 & 30 & $57 \%$ \\
\hline
\end{tabular}




\begin{tabular}{lllll}
\hline Hyun & Korean & 11 & 27 & $41 \%$ \\
\hline Oscar & Turkish & 13 & 20 & $65 \%$ \\
\hline Mengmeng & Chinese & 10 & 24 & $42 \%$ \\
\hline Jongjong & Chinese & 14 & 24 & $58 \%$ \\
\hline Xuxu & Chinese & 11 & 25 & $44 \%$ \\
\hline Huahua & Chinese & 9 & 17 & $53 \%$ \\
\hline Lee & Chinese & 8 & 25 & $32 \%$ \\
\hline Bobo & Chinese & 7 & 19 & $37 \%$ \\
\hline Ahmed & Turkish & 9 & 22 & $41 \%$ \\
\hline$*$ Class Average & & & $45 \%$ & \\
\hline
\end{tabular}

Table 8. Percentage of Use of Cohesive Devices for First Assignment (Experimental)

\begin{tabular}{llccc}
\hline Pseudonym & L1 & Sentences with Connectives & Total Number of Sentences & Percentage \\
\hline Alma & Farsi & 4 & 15 & $27 \%$ \\
\hline Xiaochen & Chinese & 7 & 25 & $28 \%$ \\
\hline Fanfan & Chinese & 8 & 18 & $44 \%$ \\
\hline Hanhan & Chinese & 7 & 22 & $32 \%$ \\
\hline Lili & Chinese & 3 & 16 & $19 \%$ \\
\hline Songsong & Chinese & 12 & 31 & $39 \%$ \\
\hline Hengheng & Chinese & 3 & 15 & $20 \%$ \\
\hline Jiajia & Chinese & 7 & 33 & $21 \%$ \\
\hline Haohao & Chinese & 7 & 26 & $27 \%$ \\
\hline Liang & Chinese & 6 & 22 & $27 \%$ \\
\hline Kim & Korean & 9 & 22 & $41 \%$ \\
\hline Santiago & Spanish & 6 & 24 & $25 \%$ \\
\hline Ibrahim & Persian & 11 & 24 & $46 \%$ \\
\hline Minmin & Chinese & 1 & 18 & $6.0 \%$ \\
\hline$*$ Class Average & & & & $29 \%$ \\
\hline
\end{tabular}

Table 7 and Table 8 demonstrate the percentage of sentences with connectives for first assignment from both groups.

In order to determine whether there is a significant difference between the experimental group and control group, Chi-square test was conducted on the data from Table 7 and Table 8 . In Table 9, numbers in the column of Sentences with Connectives and Sentences without Connectives are the average of the whole class.

Table 9. Chi-Square Analysis of Connectives for First Assignment

\begin{tabular}{lccc}
\hline & Sentences with Connectives & Sentences without Connectives \\
\hline Control Group & 11 & 13 \\
\hline Experimental Group & 7 & 15 \\
\hline
\end{tabular}


The Chi-square statistic is 0.9466 . The $\mathrm{P}$ value is 0.330592 . This result is not significant at $\mathrm{p}<$ 0.10. In other words, students' uses of connectives from both groups were at similar level at the beginning of the semester before the CCCR instruction and activities.

At the end of the semester, students' sentences with connectives from both groups were calculated to investigate whether students' use of connectives changed after CCCR instruction and activities. Table 10 and 11 demonstrate the final data of two groups on sentences with connectives in relation to total number of sentences.

Table 10. Percentage of Use of Cohesive Devices for Final Assignment from Control Group

\begin{tabular}{llccc}
\hline Pseudonym & L1 & Sentences with Connectives & Total Number of Sentences & Percentage \\
\hline Yueyue & Chinese & 16 & 102 & $16 \%$ \\
\hline Sunsun & Korean & 52 & 134 & $39 \%$ \\
\hline Kwon & Korean & 40 & 105 & $38 \%$ \\
\hline Hyun & Korean & 51 & 105 & $49 \%$ \\
\hline Oscar & Turkish & 25 & 119 & $21 \%$ \\
\hline Mengmeng & Chinese & 22 & 96 & $23 \%$ \\
\hline Jongjong & Chinese & 32 & 133 & $24 \%$ \\
\hline Xuxu & Chinese & 11 & 91 & $12 \%$ \\
\hline Huahua & Chinese & 40 & 102 & $39 \%$ \\
\hline Lee & Chinese & 16 & 67 & $24 \%$ \\
\hline Bobo & Chinese & 23 & 74 & $31 \%$ \\
\hline Ahmed & Turkish & 18 & 97 & $19 \%$ \\
\hline$*$ Class Average & & & & $28 \%$ \\
\hline
\end{tabular}

Table 11. Percentage of Sentences with Connectives for Final Assignment from Experimental Group

\begin{tabular}{llccc}
\hline Pseudonym & L1 & Sentences with Connectives & Total Number of Sentences & Percentage \\
\hline Alma & Farsi & 20 & 77 & $26 \%$ \\
\hline Xiaochen & Chinese & 45 & 132 & $34 \%$ \\
\hline Fanfan & Chinese & 40 & 69 & 113 \\
\hline Hanhan & Chinese & 59 & 115 & $52 \%$ \\
\hline Lili & Chinese & 39 & 113 & $34 \%$ \\
\hline Songsong & Chinese & 42 & 72 & $37 \%$ \\
\hline Hengheng & Chinese & 29 & 120 & $40 \%$ \\
\hline Jiajia & Chinese & 44 & 134 & $37 \%$ \\
\hline Haohao & Chinese & 49 & 103 & $37 \%$ \\
\hline Liang & Chinese & 28 & 100 & $27 \%$ \\
\hline Kim & Korean & 54 & 65 & $54 \%$ \\
\hline Santiago & Spanish & 26 & 68 & $40 \%$ \\
\hline Ibrahim & Persian & 19 & 83 & $28 \%$ \\
\hline Minmin & Chinese & 45 & $54 \%$ \\
\hline
\end{tabular}


Table 12 Chi-Square Analysis of Connectives for Final Assignment

\begin{tabular}{lcc}
\hline & Sentences with Connectives & Sentences without Connectives \\
\hline Control Group & 29 & 73 \\
\hline Experimental Group & 39 & 58 \\
\hline
\end{tabular}

Chi-square test was used to run the data between control and experimental group in terms

of use of cohesive devices for final assignment. At the significance level of 0.10 , the Chi-square statistic is 3.0645. The $\mathrm{P}$ value is 0.08 . This result is significant at $\mathrm{p}<0.10$. Based on this data, it could be concluded that experimental group wrote more sentences with connectives than the control group at the end of the semester when the CCCR study had been completed. Again, this is not suggesting that writing performance is proportional with the number of connectives, but rather students from the experimental group showed an increase in the use of connectives after CCCR instruction and activities. This change was then comparatively interpreted together with students' reflection and interviews so as to show the improvement of their metacognition of CCCR by the end of the semester (discussed in more detail in the next section).

Among the data collected including students' scores for their first and final assignments, their use of dependent clauses for their first and final assignments, and their use of connectives, the most significant improvement is seen in their use of connectives, which were used in an attempt to present a more coherence piece of writing, followed by the use of dependent clauses which were used to improve the complexity of the sentences in their writing, although their change in their numerical scores is not significant. Answering the first research question of whether students who receive CCCR instruction and participate in CCCR discussions perform better in their writings: from the rating results, students in the experimental group did not seem to be significantly better than those in the control group based on the numerical grades despite the difference of 0.29 in their grades.

\section{Results \& Discussions of Phase 2 (Student Responses)}

In Figure 1 to 9, $\mathrm{x}$-axis is the scale of 1 to 5 which shows students' subjective perception towards the discussed question, with 1 being the lowest end of the spectrum and 5 the highest, and y-axis represents the number of students. At the end of the semester, students' responses to the study of CCCR instruction were collected to supplement the numerical data. Their responses reflected the areas of CCCR instruction and discussions that the participants felt had influenced their writing 
more and their preferred delivery modes of CCCR instruction and discussions. Among the experimental group who received the CCCR instruction, their responses to the question of "On the scale of 1 to 5, how much do you think that your L1 influences your English academic writing?" are summarized below in figure 1:

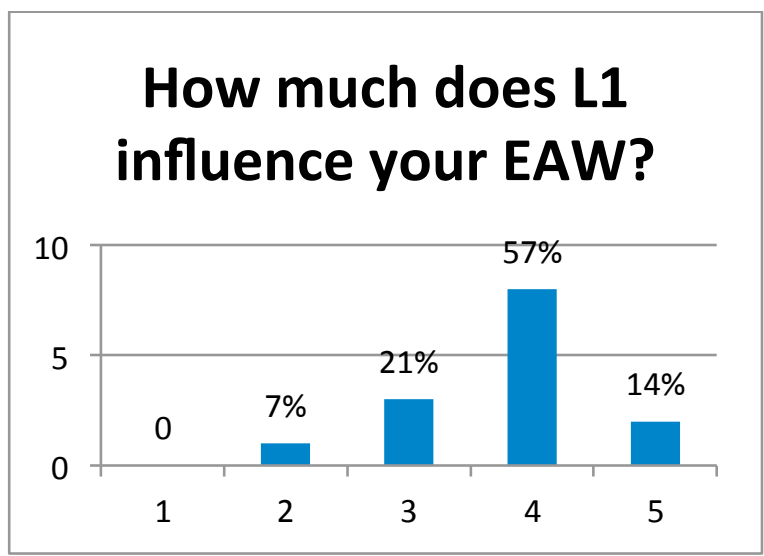

Figure 1. Students' Perceptions of How Much L1s Influence Their EAW

Among 14 students, three students were in the middle of the spectrum and 1 student rated this 2 . This finding is strongly reinforced by the experimental participants' written responses explaining their ranking. Xiaochen (Chinese) stated that, "although the English sentences she wrote was [sic] grammatically correct, they seem strange to native speakers," and Lili (Chinese) also shared the same sentiment: "I'm not used to writing sentences with (dependent) clauses. Sometimes, when I use clauses, I confuse myself. In Chinese, we have the same translations for some of the connectives and when I write academic papers, I don't know which one to use."

Kim (Korean) focused more on the sentence structural differences between Korean and English as the verb is always placed at the end of a sentence with a verb conjugation whereas this is not the case in English. He felt that this is the reason behind his incorrect English sentences. From the perspective of rhetorical organization, he contended that the body paragraph in Korean has the structure of IEP, which are illustration, explanation and point. He believed that before the CCCR intervention he was more prone to use the IEP structure instead of PIE structure in English academic writing in which the point is stated first and then the illustrations are provided with the explanation at the end connecting the illustrations and the main point of the body paragraph.

Hanhan (Chinese) reported her understanding of the influence of L1 in her English academic writing as following, "my L1 influenced my English writing in the way that I'm not good at connecting the sentences. Because in Chinese, even if there are no connection devices 
between two sentences, the paragraph is still regarded to be fluent, but in English writing, I need to apply different ways to make my article as a unity." Hanhan also agreed with the reading materials provided on the Chinese style of writing (Chen, 2005) about the use of Chinese sayings: "sometimes I use proverbs in my L1 which only make sense to Chinese speakers, and that causes confusion."

Jiajia (Taiwanese), summarized how she perceived that her L1 influenced her English academic writing thus:, "The way I structure my essay, the way I use the connectives or transitions, and sentence structure". Alma (Farsi) thought that her L1 influenced her use of punctuation marks and clauses she used in English academic writing. Haohao (Chinese) realized some problems of his shifts in English grammar were caused by direct Chinese translation, saying that, "I prefer to use long sentences. Sometimes, I just translate the Chinese sentences into English. Besides, there are a lot of shifts in my English writing, because I never heard of the concept of shifts in Chinese." Based on the above illustrations, it is clear that students in the experimental group demonstrated metacognition about how their L1 influences their English writing after the cross-cultural contrastive rhetoric study was finished.

Discussion of Research Question 2: What are the areas of CCCR instruction that play a more important role in students' writing assignments from students' perspectives?

CCCR studies and instruction were divided into four aspects: rhetorical styles, rhetorical organization, clauses and connectives. In this article, only the use of clauses and connectives were calculated. Rhetorical styles and rhetorical organizations are comparably less quantifiable and it is difficult to evaluate students' progress of rhetorical styles and organizations using quantitative data. Instead, students' subjective opinions in their reflections and surveys showed their understandings of rhetorical styles and rhetorical organizations. Students from the experimental group were asked to rate each of them in terms of how useful they think it was for improving their English academic writing. The following graphs are respective summaries of students' responses towards the CCCR instruction and discussion on rhetorical styles, rhetorical organization, clauses and connectives ( 1 denotes the least and 5 the most in the graph): 


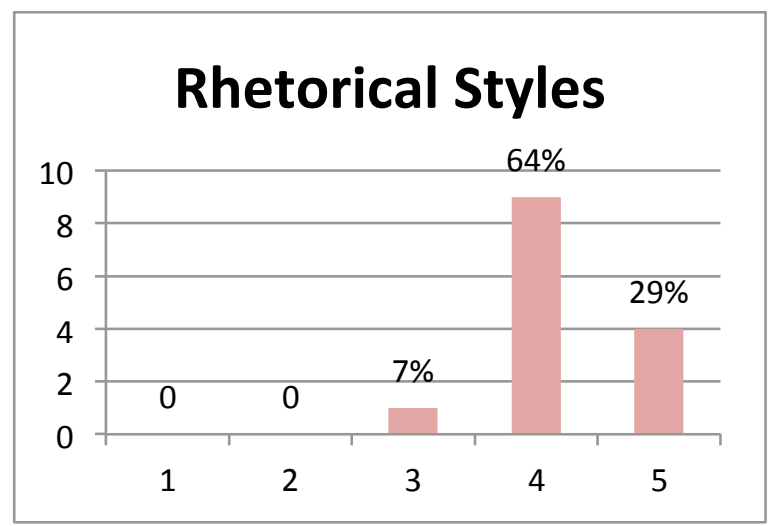

Figure 2. Rhetorical Style

The $\mathrm{x}$-axis is the spectrum showing students' subjective perceptions of the helpfulness of comparing rhetorical styles in English academic writing and academic writing in their L1s by the end of the course with 1 the least and 5 the most and the y-axis is the number of students. Figure 2 indicates that $93 \%$ of students gave a 4 and 5 on the scale of $1-5$, with 1 the lowest and 5 the highest, for rhetorical styles. The rest of the students gave a 3. It shows that students in general perceived rhetorical styles as helpful in the CCCR curriculum.helpful in CCCR curriculum.

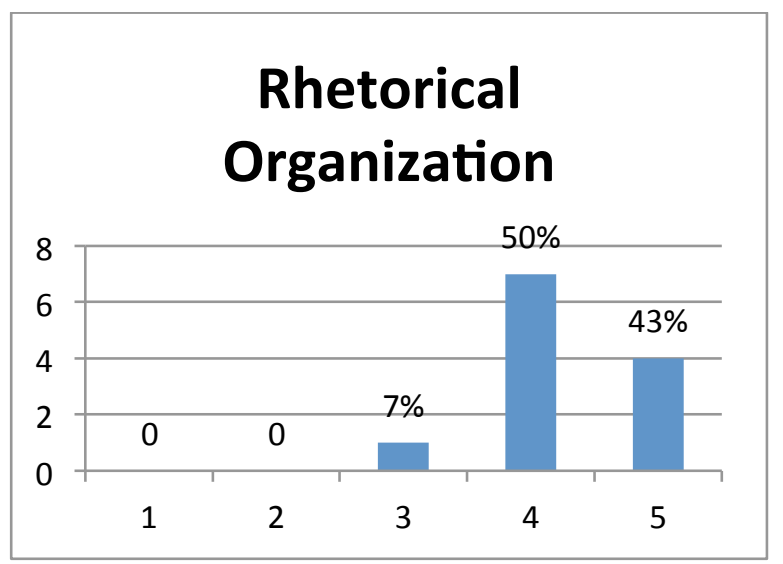

Figure 3. Rhetorical Organization

Among 14 students, 93\% of them contended that the CCCR instruction organization was helpful. Both rhetorical style and organization were discussed at the beginning of the semester, and students have repeatedly referred to these two in their reflections and questionnaires. This result informed ESL instructors that CCCR activities could be a very effective to grab students' interests in ESL writing courses that could be implemented in the courses. 


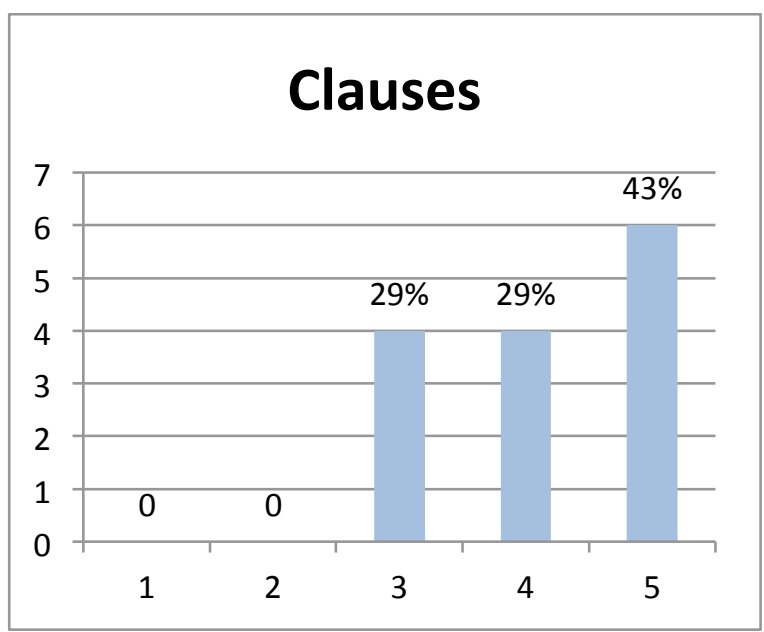

Figure 4. Clauses

Among the 14 students in the experimental group, 10 students felt that CCCR studies and instruction on dependent clauses are helpful as they rated this as 4 or five. Four students rated this as 3 and this may be due to the fact that these students are more confident with the English clauses in the first place. This could be seen in students' performance in the first assignment. There are a few students who did much better than average by analyzing the percentage of clause usage in the assignment.

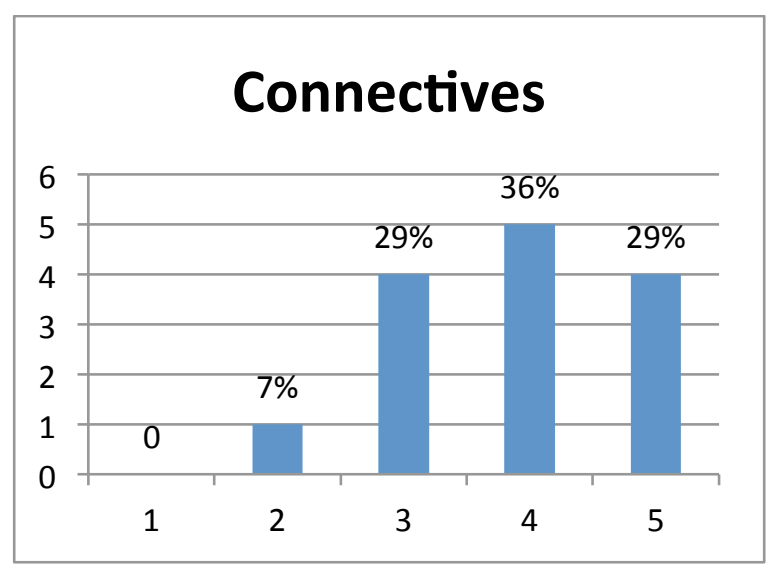

Figure 5. Connectives

Connectives, among the four aspects of the CCCR studies, received the lowest rating from the experimental group: $65 \%$ of the students thought it was helpful whereas $7 \%$ of the students did not indicate it as helpful while $29 \%$ of the students gave a rating of 3. Students' subjective perception about connectives is the opposite of their performance in their writings. Among the four categories, students' use of cohesive devices is the only data that shows significance difference between the control group and the experimental group by the end of the semester. This 
data also shows that sometimes students' subjective opinions of certain aspects of English academic writing are not accurate in making the most informed decisions.

Discussion of Research Question 3: What are the delivery modes of CCCR instruction and discussions that students respond well to?

The following graphs are students' ratings on each type of delivery mode in terms of how effective they think it is in helping them understand the differences and similarities between their L1s and English. Figure 6 demonstrates students rating of in-class instruction of CCCR: 86\% of students rated it at 4 or 5 and $7 \%$ rated it at 2 and 3 respectively. Figure 3 is students' ratings of videos of CCCR: all students gave it a rating equal or above 3 with $79 \%$ of the students rated it as 4 and 5. Figure 4 shows students' ratings of readings of CCCR: $21 \%$ of students rated it at 2 and $43 \%$ rated it at 3 , and only $35 \%$ of students rated it at 4 or 5 .

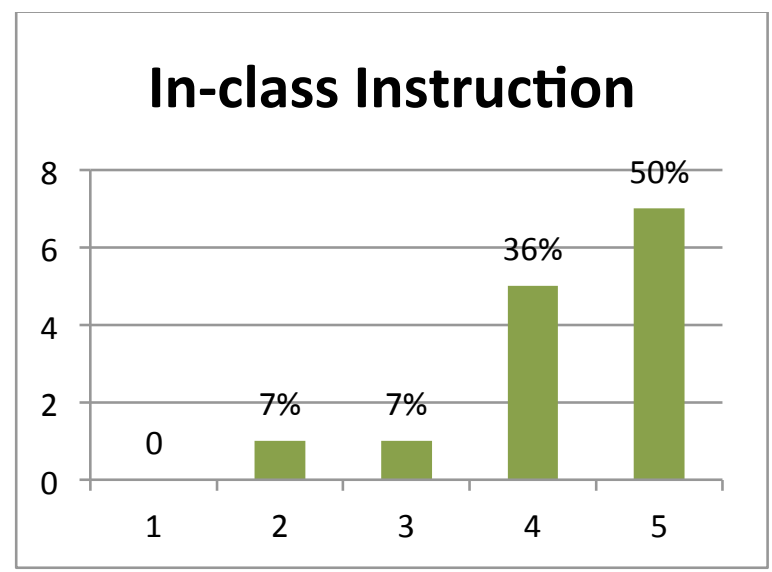

Figure 6 In-class Instruction 


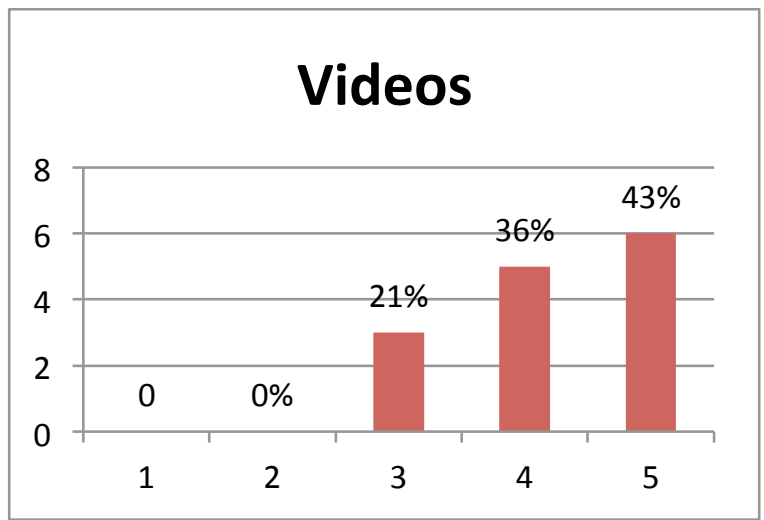

Figure 7 Videos

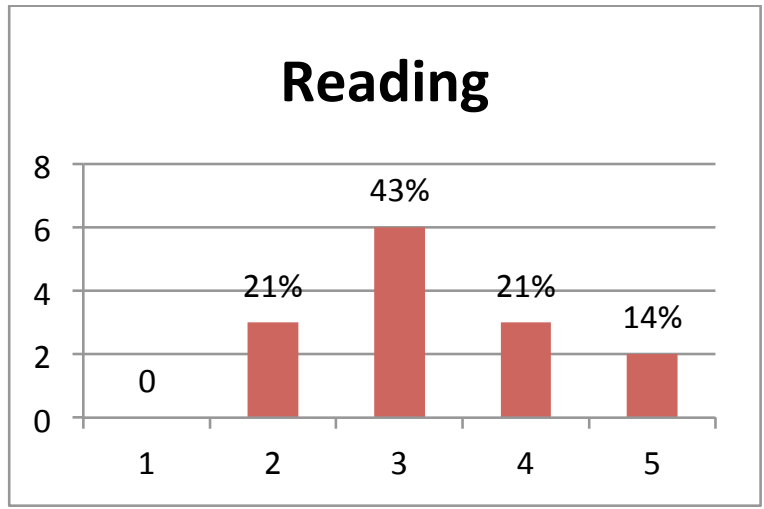

Figure 8 Reading

From Figure 6 to 8, it could be seen that students rated the videos as the most effective, in-class discussions second, and readings as least effective. This information provides some important implications to teachers who intend to incorporate some CCCR instruction in the English academic writing courses in terms of which type of delivery mode to use for different types of topics. This finding also brings up an important implication for conveying information to students in general since reading, the traditional way that large amounts of information are conveyed to students in many courses, were seen as the least effective overall.

Both the experimental and control groups were also asked at the end of the semester about their confidence level in writing in English. 


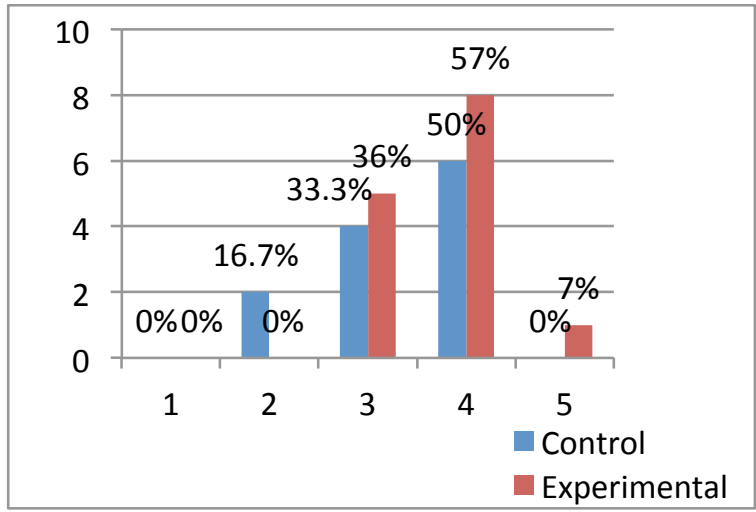

Figure 9 How Confident Students Are with EAW

Figure 9 shows that $64 \%$ of students in the experimental group gave a 4 or 5 for their confidence level which is better than the control group shown by the blue bars. Figure 9 shows that zero students from the control group gave a 5 on their confidence of English academic writing Comparing students' confidence level in the control group and experimental group, it could be seen that bars in Figure 9 that reveals students' confidence about their writing at the end of the semester are more towards the right end of the continuum of 1 to 5 compared to Figure 9 . In the experimental group, $100 \%$ of students' confidence level is above level 3, whereas in the control group $83.3 \%$ of the students' confidence level is above level 3 . The major purpose of this study is to equip students with the necessary writing skills to ensure their success in their major courses. The fact that students became more confident in English academic writing proves the possibility of applying this CCCR model in ESL writing courses and it deems its efficacy in reducing the possible affective filter that international students might have in the endeavor of English academic writing.

\section{Conclusions}

The results indicate that the pedagogy exploiting cross-cultural contrastive rhetoric could be implemented as a model for various courses of English academic courses. CCCR instruction and discussions recommended by this study is student-centered. Instead of providing students the model, rule and formulae to follow, the instructor facilitates students in the process of finding and recognizing similarities and differences between English academic writing and academic writing in their L1s in different aspects including rhetorical styles, rhetorical organization, and use of English language such as dependent clauses and cohesive devices. 
The growth of students' metacognition reflected students' knowledge of their own thinking (Kellogg, 1994) and the trajectory of their discovery of contrastive rhetoric throughout the semester traces their metacognition development which in turn helps them see how English academic writing could be shaped using their knowledge and experience of their native languages and academic writing in their native language. Future possible research could be generated based on this study: as this study lasted only one semester, students' further writing performance could not be reported. For some students, it takes longer to internalize the findings and discoveries from CCCR activities.

\section{References}

Anderson, N. J. (2008). Metacognition and good language learners. Lessons from good language learners, 99-109.

Atkinson, D. (2003). Writing and culture in the post-process era. Journal of Second Language Writing, 12(1), 49-63.

Atkinson, D. (2004). Contrasting Rhetorics/Contrasting Cultures: Why Contrastive Rhetoric Needs a Better Conceptualization of Culture. Journal of English For Academic Purposes, 3(4), 277-289.

Anderson, N. J. (2002), The role of metacognition in second language teaching and Learning. ERIC Digest EDO. Washington, OC: ERIC Clearinghouse on Languages and Linguistics.

Carrell, P. L. (1984). The effects of rhetorical organization on ESL readers. TESOL Quarterly, 18(3), 441-469.

Chen, C.-T. (2005). "Why does my English writing sound so Chinese?": A contrastive rhetoric for Taiwanese instructors of English writing. Unpublished master's thesis, Soka University of America, Calabasas, CA.

Connor, U. (2002).New Directions in Contrastive Rhetoric. TESOL Quarterly, 4(36), 493-510.

Fagan, E. R., \& Cheong, P. (1987). Contrastive rhetoric: Pedagogical implications for the FESL teacher in Singapore. RELC Journal, 18(1), 19-30.

Flavell, J. H. (1979). Metacognition and cognitive monitoring: A new area of cognitivedevelopmental inquiry. American Psychologist, 34(10), 906.

Gebhard, J. G., Gaitan, S., \& Oprandy, R. (1987). Beyond prescription: The student teacher as investigator. Foreign Language Annals, 20(3), 227-232.

Hunt, K. W. (1965). Grammatical Structures Written at Three Grade Levels. NCTE Research Report No. 3.

Gregg, J. (1983). "Contrastive Rhetoric: An Exploration of Chinese and American Expository Patterns" Unpublished manuscript. New York City Technical College.

Kachru, Y. (1997). Cultural Meaning and Contrastive Rhetoric in English Education.World Englishs, 16(3), 337-350.

Kaplan, R. (1966). Cultural thought Patterns in Inter-Cultural Education. Language Learning , 16, 1-20 
Kellogg, R. T. (1994). The psychology of writing. New York: Oxford.

Kubota, R., \& Lehner, A. (2004). Toward critical contrastive rhetoric. Journal of Second Language Writing, 13(1), 7-27.

Land, R.E.J., \& Whitley, C. (1998). Toward a pluralistic US rhetoric. In V. Zamel \& R. Spack (Eds.) Negotiating academic literacies: Teaching and learning across languages and cultures, (pp. 135-144). Abingdon: Routledge.

Leki, I. (1991). Twenty-five years of contrastive rhetoric: Text analysis and writing pedagogies. Tesol Quarterly, 25(1), 123-143.

Liebman, J. (1988). Contrastive rhetoric: students as ethnographers. Journal of Basic Writing, 7(2), 6-27.

Matalene, C. (1985). Contrastive Rhetoric: An American Writing Teacher in China. College English, 47(8), 789-808.

Matsuda, P. (1997). Contrastive rhetoric in context: a dynamic model of L2 writing. Journal of Second Language Writing, 6(1), 45-60.

Mauranen, A. (1993). Contrastive ESP rhetoric: Metatext in Finnish-English economics texts. English for specific Purposes, 12(1), 3-22.

McKinley, J. (2013). Displaying critical thinking in EFL academic writing: A discussion of Japanese to English contrastive rhetoric. RELC Journal, 44(2), 195-208.

Mohan, B. A., \& Lo, W. A. Y. (1985). Academic writing and Chinese students: Transfer and developmental factors. Tesol Quarterly, 19(3), 515-534.

Petrić, B. (2005). Contrastive rhetoric in the writing classroom: a case study. English for Specific Purposes, 24, 213-228.

Quinn, J. M. (2012). Using contrastive rhetoric in the ESL classroom. Teaching English in The Two-Year College, 40(1), 31-38.

Silva, T. (1993). Toward an understanding of the distinct nature of L2 writing: The ESL research and its implications. TESOL Quarterly, 27(4), 657-677.

Tucker, A. (1995). Decoding ESL: International students in the American college classroom. Portsmouth, NH: Boynton.

University of Illinois. (n.d.). International Students Statistics. (March 24, 2015). Retrieved from http://www.isss.illinois.edu/download_forms/stats/fa14_stats.pdf

Veenman, M. V., Van Hout-Wolters, B. H., \& Afflerbach, P. (2006). Metacognition and learning: conceptual and methodological considerations. Metacognition and learning, 1(1), 3-14.

Walker, D. (2011). How to teach contrastive (intercultural) rhetoric: some ideas for pedagogical application. New Horizons In Education, 59(3), 71-81.

Yang, L. \& Cahill, D. (2008). The rhetorical organization of Chinese and American students' expository essays: a contrastive rhetoric study. IJES, 8(2), 113-132.

\footnotetext{
'Videos of instruction of dependent clauses can be found at:

http://tinyurl.com/kjz3y9g

http://tinyurl.com/qb2k4k3

http://tinyurl.com/p5z4ujh
} 
Author Information

Lin Zhou graduated from University of Illinois at Urbana-Champaign with a MASTERS degree of Teaching English as a Second Language. She did this study on pedagogical approach employing cross-cultural contrastive rhetoric as her thesis project and her thesis advisor was Dr. Randall Sadler.

Email: linzhou2@illinois.edu

To cite this article:

Zhou, L. (2016). Is there a place for cross-cultural contastive rhetoric in English academic writing courses?

Bellaterra Journal of Teaching \& Learning Language \& Literature, 9(1), 47-90. DOI:

http://dx.doi.org/10.5565/rev/jt13.645 